ArtefaCToS. Revista de estudios de la ciencia y la tecnología

eISSN: $1989-3612$

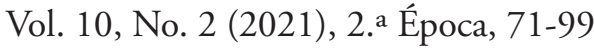

DOI: https://doi.org/10.14201/art20211027199

\title{
Nuevas tecnologías, promesas y alienación tecnológica: una mirada crítica del fenómeno del voto electrónico como dispositivo técnico moderno
}

\section{New Technologies, Promises and Technological Alienation: A Critical View at the Electronic Voting Systems as a Technical Modern Device}

\author{
Marcelo José GARCÍA FARJAT \\ Centro de Estudios Avanzados, Universidad Nacional de Córdoba, Argentina \\ garciaf_marcelo@live.com
}

Recibido: 24/03/2021. Revisado: 01/06/2021. Aceptado: 30/08/2021

\section{Resumen}

El presente artículo tiene como objetivo central caracterizar y discutir ciertas problemáticas que encierran los dispositivos electrónicos de votación desde una mirada sociológica y filosófica de la tecnología que sea capaz de tensionar algunos de los presupuestos y prenociones que subyacen a los intentos de modernizar los sistemas tradicionales de voto. En un contexto signado por la fascinación por las nuevas tecnologías, distintas voces se encargan de subrayar las presuntas ventajas de la votación electrónica como solución ante las dificultades que enfrenta la votación tradicional. Así, frente a las promesas y expectativas que envuelven a las narrativas tecnofílicas en torno a su implementación, también se busca poner en discusión ese cariz tecnooptimista que impregna a los discursos públicos a la luz de diferentes estudios que conciben al dispositivo del voto electrónico como una caja negra, al inhabilitar el control y auditoría del voto por parte de la ciudadanía. Por consiguiente, en tanto sistema opaco y cerrado, estos dispositivos aparecen como un fiel representante de la alienación tecnológica.

Palabras clave: sistemas electrónicos de votación; nuevas tecnologías; promesas; alienación tecnológica; caja negra. 


\begin{abstract}
The main objective of this article is to characterize and discuss certain problems inherent to the electronic voting systems from a philosophical and sociological technological views so that it is able to put into discussion some of the assumption that underlie the attempts to modernize the traditional voting system.

In a context marked by the fascination for new technologies, different voices are in charge of highlighting the presumed advantages of electronic voting as a solution to the difficulties faced by traditional voting systems. Thus, in the face of the promises and expectations that surround the technophile narratives around their implementation, the article seeks, also, to put in tension that optimistic look that permeates public speeches in the light of different experts who conceive the electronic voting device as a box black by disabling the control and auditing of the vote by the citizens. Consequently, as an opaque and closed system, voting technologies devices appear as a faithful exponent to the technological alienation.
\end{abstract}

Keywords: electronic voting device; new technologies; promises; black box; technological alienation.

\title{
1. Introducción
}

La implementación del voto electrónico genera muchos adeptos. Políticos, empresarios - por intereses de diversa índole-y parte de la opinión pública consideran que es absurdo proseguir con el sistema tradicional de votación. Enorme gasto público, lentitud en el recuento de votos, ahorro de papel, mayor acceso a las personas para ejercer el sufragio, mayores facilidades de votación ciudadanos con discapacidad, la reducción de gastos en términos de personal y una mayor agilidad para el conteo (Abu-Shanab, Knight y Refai, 2010, Nardi y Maenza, 2017) en adición a su presunta capacidad de superar la apatía de los votantes (Lauer, 2004) son solo algunos de los motivos aducidos por quienes defienden, con marcado optimismo, la adopción de este sistema para resolver procesos electorales. En esta línea de pensamiento, Alguiyev y Yusifov (2018) destacan que, con la postulación del concepto de e-voting, se aspira a la reducción de los errores propios de los procesos electorales tradicionales, a la vez que se busca mantener su integridad. En este trabajo, este concepto es usado para expresar y referirse a la votación mediada por tecnologías informáticas; siendo la votación por Internet, una de sus formas ${ }^{1}$ (Alguliyev y Yusifov, 2018).

\footnotetext{
${ }^{1}$ Como bien expresan Nardi y Maenza $(2017,61)$ los sistemas de votación electrónica comprenden, al menos tres categorías conceptuales y tecnológicamente, diferentes: a- la lectura automatizada de votación en papel, b- la votación en medio electrónico autónomo y c- la votación electrónica en red.
} 
Nuevas tecnologías, promesas y alienación tecnológica: una mirada crítica del fenómeno del voto electrónico como dispositivo técnico moderno

Más allá de la fascinación que despiertan las actuales tecnologías en vastos sectores de la población, la introducción (o no) del voto electrónico es extensamente debatido por expertos de diferentes áreas, quienes cuestionan su validez técnica al encontrar en los dispositivos de votación electrónicos, múltiples fallas que socavan varios de los principios fundamentales de los sistemas democráticos. A modo de contextualizar lo expresado, es posible citar algunas experiencias de capital importancia (Holanda, Alemania y Estonia) que grafican varios de los problemas que enfrentan los sistemas electrónicos de votación. En Holanda se decide en 2006, luego de detectarse vulnerabilidades significativas que comprometían la seguridad e integridad electorales ${ }^{2}$, reevaluar el uso de tecnologías para votar, dejando sin efecto su utilización; aunque desde de su abandono, se han evidenciado distintos intentos que reclaman enfáticamente su reintroducción (Loeber, 2014). Por su parte, Alemania dispuso su interrupción en 2009, cuando el máximo tribunal declaró su carácter inconstitucional, dado que los votantes no eran capaces de auditar la forma de votación (Nardi y Maenza, 2017). En un marco general de objeciones a las variadas dificultades que acarrea su empleo, se destaca el papel de la asociación de hackers más grande de Europa, el Chaos Computer Club (CCC) como uno de los grupos más críticos en torno a su aplicación. Fundado en Berlín, sus demandas principales se estructuran en torno a la libertad de información y a una mayor transparencia gubernamental. Manipulabilidad, violación del secreto de voto y problemas de seguridad son solo algunas de las dificultades que albergan estos sistemas electrónicos, visibilizadas y denunciadas por dicho grupo:

Existen dos requisitos centrales que comprenden a una elección en una democracia. El proceso de elección debe ser comprensible y a la vez, el voto debe permanecer secreto. La urna es un invento fantástico, puesto que logra armonizar ambos requisitos. Digitalmente, eso no es posible. (Neumann, 2019) $)^{3}$

En Estonia se presentaron problemas similares en torno a su introducción. Más allá de ser declarado como seguro y confiable, el sistema demostró significativas falencias vinculadas a la seguridad y confiabilidad del sistema que dejan al descubierto amplias posibilidades de ataque, fraude y errores (Springall et al., 2014). La mayoría de los esquemas electrónicos de votación propuestos en la literatura específica hacen uso de técnicas criptográficas para alcanzar una adecuada verificación extremo a extremo (end-to-end verifiability). Sin embargo, el sistema

\footnotetext{
${ }^{2}$ En esta trama, cabe destacar la conformación del grupo "we don't trust voting computers", liderado por el hacker y uno de los fundadores de la compañía proveedora de servicios de Internet xs4all, Rop Gonggrijp. Nacido luego de la celebración, en marzo de 2006, de las primeras votaciones municipales electrónicas en Amsterdam, sus preocupaciones giran en torno a su seguridad y a su falta de auditabilidad, buscando generar conciencia y debate públicos acerca de su uso y de los diversos inconvenientes que trae consigo la introducción de estos sistemas electrónicos para los sistemas democráticos.

${ }^{3}$ Traducción realizada del alemán por el autor.
} 
Nuevas tecnologías, promesas y alienación tecnológica: una mirada crítica del fenómeno del voto electrónico como dispositivo técnico moderno

estonio no hace uso de este tipo de sistema, al emplear un diseño simple a expensas de tener que confiar implícitamente en la integridad de las computadoras de votos, en los componentes de servicio y en la elección del staff (Springall et al., 2014). En esta línea crítica, señalan la existencia de formas de manipulación que caracterizan al sistema, donde criminales electrónicos expertos son capaces de alterar los votos, comprometiendo su carácter secreto y la integridad y validez de los resultados.

A partir de lo expresado, la presente propuesta de análisis busca advertir y caracterizar algunos de los presupuestos filosóficos y sociológicos subyacentes a su implementación en una época dominada por las nuevas tecnologías y por la fascinación que despiertan en las sociedades capitalistas. Consecuentemente, además de mostrar la inadecuación de la "caja de herramientas" ofrecida por el solucionismo tecnológico para solventar las dificultades que afronta la política tradicional, problematizar al dispositivo del voto electrónico alejado de nociones deterministas e instrumentalistas que, arraigadas en el imaginario colectivo, resulta de particular interés para los objetivos de este trabajo. Particularmente, estas tesituras omiten el carácter procesual y contingente de las tecnologías; cuyas modalidades de desarrollo se hallan atravesadas por dimensiones políticas, económicas, sociales y tecnológicas. Por consiguiente, un punto de partida conceptual para el tratamiento del dispositivo de voto electrónico estriba en la consideración, tanto de sus peculiaridades y funcionalidades como sistema, como también la valoración de la complejidad inherente a sus procesos de construcción, corporización y difusión en circunstancias determinadas. Las aspiraciones de extensión y de acoplamiento de los sistemas de votación a los cánones del progreso moderno y del solucionismo tecnológico se anclan en miradas reduccionistas de la técnica que reducen lo tecnológico a sus usos y efectos y a su eficiencia en términos estrictamente técnicos y productivos. Ello, en el marco de una historia lineal y evolutiva que emparenta los triunfos tecnológicos con el éxito de estos productos tecnológicos que circulan en el mercado. La máxima "lo que triunfa es lo mejor" (que condensa el espíritu determinista y capitalista imperantes) permea, no solo a las narrativas economicistas imperantes, sino también a muchos de los estudios sobre ciencia, tecnología y sociedad.

Desde esta línea argumentativa aparece un problema no menor que va a guiar el análisis del objeto en cuestión: la difusión y establecimiento de tecnologías hegemónicas, opacas y cerradas que performan y modelan nuestro "estar en el mundo" y que dan sentido a la cultura técnica imperante. Lo manifestado resulta de particular interés, en tanto que los sistemas de votación electrónicos responden a aquel tipo de tecnologías alienantes, desarrolladas y criticadas, entre otros pensadores, por Quintanilla:

(...) la alienación tecnológica no se produce solamente en el uso de maquinaria (bajo control del propietario del capital) por parte del trabajador en el proceso productivo, sino en el uso de la tecnología en general, si esta 
Nuevas tecnologías, promesas y alienación tecnológica: una mirada crítica del fenómeno del voto electrónico como dispositivo técnico moderno

no se ha diseñado de la forma adecuada para que el usuario mantenga el control sobre ella, circunstancia que, en principio, es independiente del régimen de propiedad bajo el que funciona la tecnología. (Quintanilla, 2017a, 21)

Entre otras características, estos sistemas informatizados se distinguen, siguiendo los trabajos de Quintanilla (2017a, 2017b) por ser tecnologías cerradas y no colaborativas, cuyo diseño y estructura físicos se encargan de ocultar sus funciones y propósitos reales a la vez que anulan la participación y control ciudadanos. En otras palabras, se presenta como una "caja negra", impenetrable en su significado y funcionamiento para los usuarios, imposibilitados de conocer lo que sucede dentro de una urna electrónica, en una época signada por avances siderales en el campo informático que solo unos pocos especialistas son capaces de comprender y explicar.

Desde su opacidad estructural y conformación física, distintos expertos (informáticos, ingenieros, abogados, politólogos, por mencionar algunos) alertan insistentemente sobre los riesgos significativos a los que se exponen las democracias representativas con la introducción del sistema de voto electrónico (Springall et al., 2014; Neumann, 2018; Montes et al., 2016; Abu-Shanab et al., 2010; Quilomba, 2017; Alguliyev y Yusifov, 2018; Bishop y Wagner, 2017; Lauer, 2004). Por lo tanto, y más allá de cumplir con algunas de sus promesas, el sistema parece no poder satisfacer las expectativas de garantizar integridad, confiabilidad, transparencia y auditabilidad; socavando, de esta forma, los principios pilares de los sistemas democráticos: el voto libre, secreto y universal.

Tomando como eje lo referenciado, el trabajo se estructura de la siguiente forma. En primer lugar, se busca dar cuenta de cómo el voto electrónico aparece como un fiel emblema de los mandatos y promesas del progreso moderno en un contexto marcado por la fascinación y deslumbramiento por las nuevas tecnologías. En segundo lugar, se pretende relevar y discutir algunas inadecuaciones de la ideología solucionista para resolver los problemas que hoy afrontan los sistemas de votación tradicionales, a la vez que se busca problematizar su inclusión a partir de enfoques deterministas e instrumentalistas que permean y estructuran al imaginario colectivo. Finalmente, y alejado de nociones deterministas e instrumentalistas, se intenta arrojar luz sobre ciertos problemas de cariz sociológico y filosófico que giran en torno a la opacidad estructural del diseño y estructura de los sistemas de votación electrónicos.

\section{El voto electrónico como fiel representante de las promesas del progreso moderno}

La fascinación por lo tecnológico no es nueva. Pero este fenómeno cobra nuevos matices en el marco de lo que Castells (2000) denomina la revolución de la tecnología, puesto que ha alterado las bases materiales de la sociedad, generando 
Nuevas tecnologías, promesas y alienación tecnológica: una mirada crítica del fenómeno del voto electrónico como dispositivo técnico moderno

profundos cambios en la cultura, la política y la forma de comunicarnos entre los seres humanos. El espiral de cambios tecnológicos que caracteriza a la época actual forma parte de un nuevo entramado tecnosocial que demanda la revisión y redefinición de conceptos tales como la vida, la subjetividad y los objetos en un contexto que reclama actualizaciones teórico-conceptuales constantes que sean capaces de constatar y dar respuesta a los nuevos sentidos y problemáticas que emergen a partir del advenimiento finisecular de las nuevas tecnologías. Y en este sentido, los intentos de modernizar los sistemas de votación ${ }^{4}$ no escapan a dicha tendencia. Se inscriben en un escenario que reconoce la primacía de la información y la comunicación en la estructura y desarrollo de las sociedades digitales actuales. Intentos que, siguiendo a Lash (2006), forman parte de los procesos de informatización de los objetos materiales, en una era que advierte el carácter global de la cultura, que da cuenta del paso de una lógica industrial a otra de orden informacional, en donde la información y la comunicación desplazan a lo económico como eje central de lo que Flusser (2002) concibe como fase "poshistórica"; caracterizada por la producción de símbolos en desmedro de las "cosas" ,propio de la era industrial. En esta estela de caracterizaciones que buscan poner de relieve el rol medular de lo digital, no se puede soslayar la predominancia incontestable de los algoritmos en prácticamente todas las esferas de la vida en lo que Striphas (2015) define como cultura algorítmica.

Tomar como eje de análisis la virtual omnipresencia de las nuevas tecnologías en la cotidianidad, donde los algoritmos articulan y dirigen nuestros modos de pensamiento y de acción, resulta de particular interés para situar y visualizar qué relación (y bajo qué presupuestos y prenociones) mantiene el ciudadano (y sus diseñadores, promotores y publicistas) con las tecnologías informáticas de votación y que expectativas y aspiraciones instrumentan dicha relación a la luz de las promesas vertidas por quienes impulsan con marcado énfasis, su incorporación. Las pretensiones de modernizar los sistemas electorales se fundan en variadas promesas que, enmarcadas en la constante del progreso y de la innovación tecnológica, parecen ser difíciles de resistir para gran parte de la ciudadanía: agilidad, eliminación del clientelismo político, disminución del fraude electoral, mayor accesibilidad y ahorro de papel son solo algunos de los beneficios preconizados:

se lo presenta como un sistema que nos ayudará a mejorar la democracia, partiendo del desmantelamiento del aparato partidario y el punterismo, hasta el fomento de la participación ciudadana, como si la inclusión de tecnologías en el acto de votar lo revistiera de transparencia, celeridad y, por sobre todo, modernidad. (Busaniche y Heinz, 2008, 14)

\footnotetext{
${ }^{4}$ Cabe resaltar que las propuestas de modernizar los procesos electorales, basadas en el potencial de las tecnologías, no es algo nuevo. Una de las primeras aplicaciones de las tecnologías electromecánicas de finales del siglo XIX fue su uso para el ejercicio del voto electrónico y del recuento posterior de papeletas (Panizo, 2007).
} 
Nuevas tecnologías, promesas y alienación tecnológica: una mirada crítica del fenómeno del voto electrónico como dispositivo técnico moderno

Ante este optimismo, Bishop y Wagner (2017) alertan que la votación electrónica se ha expandido a una escala global sin prestar ka suficiente atención a su confiabilidad, seguridad y transparencia, más allá de sus pretensiones iniciales de reducción (manifiestas por varios de sus impulsores) de los errores propios de los procesos electorales y de mantener su integridad. La votación mediada por tecnología no es una mera nueva forma de ejercer el sufragio. Por el contrario, es plausible de generar cambios significativos en la imagen ya establecida acerca de lo que es el voto y, en definitiva, de la democracia (Pieters y Becker, 2005); de promover cambios en el imaginario democrático.

Los llamamientos por su incorporación forman parte de un reclamo sistémico que demuestra un singular interés por la adopción de nuevas tecnologías en cada vez más sectores de la vida; interés basado en la capacidad de simplificar y solucionar distintos problemas que aquejan a las sociedades presentes. En tiempos de expansión y fascinación tecnológicas, se presenta válido hacer uso del concepto de imaginario mágico algorítmico propuesto por Cabrera (2021) para dar cuenta del carácter prometeico y salvador que se le atribuye a los dispositivos electrónicos de votación como respuesta a los variados inconvenientes que encierran los procesos de votación tradicional:

Se entiende por imaginario mágico algorítmico al conjunto de significaciones que hacen posible el funcionamiento social de tecnologías digitales. Es decir, un conjunto de creencias que definen concretamente un significado, «algoritmo", para "explicar» un modo de experimentar la tecnología que justifica y legitima lo social tal como aparece dado. (Cabrera, 2021, 126)

Un punto central de la discusión descansa en como su efectividad (material) aparece como una experiencia mágica para los votantes, quienes, al omitir sus variados y heterogéneos procesos de materialización social y las relaciones sociales que lo instituyen como tal, se maravillan ante la simplificación y eficiencia técnica que demuestran los procesos de votación digitales. En este contexto comulgan, por un lado, la creciente delegación de nuestras capacidades deliberativas, afectivas y de acción a los designios tecnológicos en las culturas mediadas por algoritmos. Y por otro, el desconocimiento y la falta de entendimiento de los mecanismos y de los procesos tecnológicos y sociales que cimentan la simplificación recién aludida ${ }^{5}$. Ante la exactitud y objetividad que distinguen a los algoritmos, se torna imperativo, a fin de mantener e intensificar un vínculo asimétrico y asincrónico y de independencia de cualquier tipo de subjetividad entre lo algorítmico y los ciudadanos, el ocultamiento de las relaciones sociales que lo materializan y lo consagran como tal: "la marca humana debe quedar olvidada" (Cabrera, 2021, 134).

\footnotetext{
${ }^{5}$ Hecho que facilita, tal como se verá en apartados subsiguientes, la expansión y naturalización de la neutralidad tecnológica como eje vertebrador del imaginario colectivo en torno a la relación del ciudadano con lo tecnológico.
} 
Nuevas tecnologías, promesas y alienación tecnológica: una mirada crítica del fenómeno del voto electrónico como dispositivo técnico moderno

La simplificación impulsada y forjada por las nuevas tecnologías al momento de ejercer sufragio es tangible, a modo de ejemplo, al constatar su potencia realizativa por medio de una tecla, un botón o una pantalla táctil. Lo mencionado opera como fiel emblema de una relación desigual con esta tecnología al ocultar sus prestaciones y mecanismos fundantes, pero que cumple, desde un parámetro técnico, con varios de los objetivos y promesas publicitados, y esperados por los usuarios; cuya presencia y desenvolvimiento se solidifican y se naturalizan en tanto síntoma epocal de las sociedades informatizadas. Sociedades caracterizadas por el enaltecimiento y la confianza indubitable en las capacidades transformadoras de las tecnologías digitales: la magia y el asombro alimentan una subjetividad entregada anímicamente a sus aparatos (Cabrera, 2021, 141).

Ante las diversas fallas que albergan los sistemas tradicionales de votación, donde, entre otras cuestiones, el error, la corrupción, lentitud en el conteo de votos y negligencia humanas aparecen como blanco permanente de críticas, la magia de la velocidad, exactitud e imparcialidad (Cabrera, 2021) que ostentan las nuevas tecnologías, premoldea y sustenta el apoyo y la necesidad antropotécnica del sujeto de completarse y perfeccionarse ante la eficiencia palmaria de los dispositivos, dando lugar a subsunción individual y colectiva a los mandatos de lo digital. En esta trama, el papel de los algoritmos como mediadores entre las interacciones que se entretejen entre el votante y la máquina desempeńa un rol medular para hacer efectiva la capacidad resolutiva de lo maquínico: "El algoritmo puede postularse en su dimensión imaginaria porque su espacio está en el «entre» de lo que aparece como interfaz, en las brechas del espacio de interacción máquina-usuario, lo que se escapa entre la mirada funcional" (Cabrera, 2021, 139).

Lejos de una concepción funcional y artefactual, el algoritmo revela, desde la óptica de Cabrera Altieri y Egea (2020), su carácter simbólico e imaginario, al actuar en los sujetos y en las sociedades como un ente independiente y autónomo que lo explica; ese "entre" imperceptible recién explicitado, de capital importancia para entender y situar el comportamiento, los significados, deseos y aspiraciones de los usuarios que fundan y dan forma al optimismo imperante que reclama la incorporación tecnológica en los procesos de votación. Y que en definitiva, esta relación de cariz tecnofílica que se tiende con estos dispositivos no es ajena a la cultura técnica actual que moldea y configura las experiencias de los sujetos con las tecnologías y las significaciones y sentidos atribuidos.

Profundizando lo dicho, las nuevas tecnologías aparecen como superadoras de la religión y la política al cumplir lo que promete: se trata de estimular la imaginación con promesas que están en pleno proceso de gestación: se promete lo que (ya) se está haciendo en los laboratorios y las fábricas (Cabrera, 2006). Guardan fuerte similitud con el relato mesiánico, como sujeto y objeto de espera de lo que vendrá necesariamente; dotadas de voluntad propia, cuya presencia habilita a pensar en un futuro mejor (Cabrera, 2006, 178). Las promesas, entonces, se 


\footnotetext{
Marcelo José García Farjat

Nuevas tecnologías, promesas y alienación tecnológica: una mirada crítica del fenómeno del voto electrónico como dispositivo técnico moderno
}

(auto)cumplen proféticamente, reforzando a la vez, la autoridad de empresas y de discursos tecnofílicos que encuentran en la tecnología, la panacea a todos los problemas que exhiben los modos tradicionales de votación. Dicho de otro modo, se presentan como promesas creíbles (generadoras de confianza ciega) dispuestas a ser cumplidas: esperanzas teñidas de modernización y marcado optimismo en las nuevas tecnologías que vienen a solucionar y superar los problemas que se desprenden de la votación en papel: "El voto electrónico es quizás el ejemplo más claro y elocuente de esta tecnofilia, de esta idea de utopía tecnológica, de que las tecnologías van a salvar al mundo, o van a salvar los problemas" (Fundación Libre, Un viaje cine y Quilomba, 2017); "se plantea como solución obvia el uso del voto electrónico” (Montes, Penazzi y Wolovick, 2016, 297).

Este carácter prometeico y salvador atribuido a las tecnologías no es propio del siglo XXI. Sus orígenes se remontan a los albores del pensamiento moderno. Como bien indica Berardi (2019), desde entonces, la técnica se erige como la encargada de solucionar los problemas antes adjudicados a la religión; dando lugar a lo que el pensador italiano concibe como "teocracia técnica". En un razonamiento similar, la tecnología se instituye como una segunda solución creadora capaz de completar los designios de Dios (Winner, 2016). La técnica se halla imbuida de anhelos y esfuerzos espirituales que atestiguan, siguiendo a De Barros $(2018,13)$, la permanencia en la existencia de lo mágico en muchas de las tecnologías actuales, su capacidad para hacer creer; las técnicas que se dirigen a sumar a la fe; y que rompen con las leyes naturales (Guevara Pezoa, 2019).

En este espectro de discusiones, las nuevas tecnologías, en su condición de tecnociencia, disponen de un rasgo distintivo fundamental que no puede ser omitido para una mejor comprensión del fenómeno del voto electrónico: el hecho de ser un producto de mercado financiado y gestionado por empresas privadas, apoyado y difundido por la publicidad y el Marketing (Cabrera, 2006, 161). De esta forma, siguiendo la argumentación del citado Cabrera, es posible advertir en los medios de comunicación, discursos y estrategias de promoción dirigidos, por un lado, a dar respuestas, tanto a los miedos y temores que puede suscitar la votación electrónica, como a las esperanzas sociales identificadas, relevadas y sistematizadas por las empresas y organizaciones (de diversa índole) a través de diversas técnicas y herramientas que envuelven a las prácticas mercadotécnicas. Por otro lado, busca estimular y encender la imaginación bajo los rótulos de la novedad y la eficacia técnica de estos aparatos. Si bien el análisis de los medios de comunicación y de las estrategias de Marketing en este contexto de discusiones excede las pretensiones del presente trabajo, alcanzar destacar como parte del poder público y mediático se encarga de resaltar a la ciudadanía los beneficios y ventajas que trae consigo la implementación del voto electrónico, minimizando, al mismo tiempo, sus desventajas y riesgos, actuando como vectores de información que potencian y enrobustecen sentimientos tecnofílicos ante el incontestable 
Nuevas tecnologías, promesas y alienación tecnológica: una mirada crítica del fenómeno del voto electrónico como dispositivo técnico moderno

desarrollo tecnológico y el bienestar material ofrecido a los consumidores, a la vez que instituye una familiarización dogmática con lo tecnológico que lo aleja de una actitud crítica y de distanciamiento frente a su inaprensible presión ubicua.

Desde estas puntualizaciones, es plausible subrayar que, frente al deslumbramiento y la confianza inusitada que despiertan los avances tecnológicos en los usuarios, la capacidad crítica ante su ubicuidad y su efectividad técnica se evapora, en tiempos de aceleración tecnosocial y del ritmo de vida. Las nuevas tecnologías, manifiesta Cabrera, en tanto que significación imaginaria social y revestida de temporalidad, aparecen como el rostro del nuevo optimismo contemporáneo: "la eficiencia de los aparatos técnicos nos indicaría que vivimos en "el mejor de los mundos posibles" (2006, 203). Eficiencia que se torna visible en el buen funcionamiento técnico, y en consecuencia, en sus resultados: la tecnología nos da poder y nos permite el ejercicio de la libertad humana, en donde este buen funcionamiento, producto de la acción intuitiva del usuario, respalda la confianza que experimenta el usuario ante la eficacia técnica que muestran los dispositivos de votación electrónica.

Dicho esto, la incorporación del e-voting refleja fielmente este espíritu tecnooptimista que alimenta las esperanzas de un futuro mejor ante las ventajas promocionadas por sus impulsores, amparadas también en la presunta neutralidad valorativa que encierran estos dispositivos electrónicos. En efecto, los intentos y expectativas de modernizar los sistemas de votación parecen no encontrar hostilidades significativas por parte de la opinión pública, en un escenario que reclama su urgente adaptación a los parámetros y cánones de productividad y modernización subyacentes al paradigma economicista imperante. Las representaciones y creencias que articulan los usos de los objetos responden a la necesidad (heterodigirida) de adaptación y de adopción de estos objetos que orbitan nuestra vida diaria: los sujetos deben adaptarse a riesgo de quedar excluidos (Musso, 2009) de la ola de avances tecnológicos y de la posibilidad de hacer usufructo del desarrollo tecnocientífico imperante. Las tecnologías actuales se muestran como un curso inevitable que conduce a la humanidad a su destino (Cabrera, 2006, 134). Pensando en los dispositivos de votación electrónica: "era algo ineludible, era algo que iba a pasar, una forma de determinismo de que ese iba a ser el destino, íbamos a ir hacia ahî" (Fundación Libre et al., 2017). Este telos finalista que se le confiere se enmarca, siguiendo a Winner (2016), en la constante del megadiscurso del progreso y de las creencias y concepciones que lo configuran y lo sostienen. Constante que permite ubicar y trazar el comportamiento y las trayectorias de acción de los sujetos en el marco de una sociedad consumista que glorifica sus cualidades. En esta línea argumentativa, Beck expresa que el progreso "es el sustitutivo del cuestionamiento, una especie de previa aceptación de fines y consecuencias que ni se conocen ni se mencionan" $(1998,238)$. Hecho que anula y clausura todo tipo de queja frente a la (creciente) elevación de vida material (de orden cuantitativo) que gozan los usuarios en nuestro tiempo. 
Modernización y progreso convergen al encargarse de indicar la irremediabilidad de las nuevas tecnologías: el futuro como expectativa de un mundo mejor y sin incertidumbres ilustra la época actual (que incluye, por cierto, a las narrativas en torno a la inclusión de la tecnología para el voto). Se manifiestan, destaca Cabrera $(2006,185)$, como imposibles de detener, son el destino de la humanidad; y de este modo, no pueden ser negadas: "el progreso tecnológico no se puede detener" (Sartori, 1998, 50). Prevalecen en el imaginario efectivo posiciones deterministas de la tecnología que sustentan dicha irremediabilidad y finalismo: "Se disputa lo antiguo frente a lo moderno. Se ha instalado la noción de que la única solución a los viejos problemas de la política es el voto electrónico, como si este fuera un inevitable acto de evolución” (Quilomba, 2017). El imperativo tecnológico señala que solo debemos adaptarnos a los cambios (Cabrera, 2006). Concepción que avala y sustenta el marcado triunfalismo que predomina en muchos discursos públicos que defienden con marcado énfasis su introducción.

\section{El dispositivo del voto electrónico visto a la luz del solucionismo tecno- lógico}

Dando continuidad a lo expuesto en párrafos precedentes, los llamados a la introducción del voto electrónico se amparan en la necesidad de hacer usufructo de las bondades que ofrecen las nuevas tecnologías, a fin de reformar los sistemas de emisión tradicionales y de adaptarlos a las exigencias del desarrollo tecnológico vigente. Las promesas de modernización del sistema se estructuran en narrativas que le adjudican a las innovaciones tecnológicas un carácter intrínsecamente positivo para el desarrollo y bienestar del cuerpo social, enmarcado en lo que Morozov (2016) entiende como solucionismo tecnológico. Esto es, prevalece una ideología preocupada en promover y estimular cambios en (prácticamente) todas las esferas de la vida cotidiana: "no sorprende que Silicon Valley ya esté inundando de planes para mejorar casi todo lo que existe sobre la faz de la tierra: la política, los ciudadanos, la edición, la cocina" (Morozov, 2016, 23). Lejos de miradas solucionistas, Bijker (2005) señala la sobrevaloración de los impactos de la tecnología sobre la democracia cuando se la presenta como solución a problemas de legitimidad política. Su uso debe concitar la atención, no solo desde lo tecnológico (de por sí problemático intrínsecamente), sino también a partir de las actitudes, demandas y habilidades sociales y valores de los ciudadanos en favor de concepciones y miradas que tomen como punto de partida conceptual y operativo, una tecnología particular, contextualizada y situada: lo que funciona en los Estados Unidos, no necesariamente lo hace en Europa. A modo de ejemplo, en Brasil, pese al éxito inicial en el 2000, la falta de confianza pública en el sistema y la situación crítica que vive su población, suscitó un fuerte rechazo al uso de la tecnología para votar (Hapsara, Imran y Turner, 2017).

En esta trama, las firmes intenciones de adoptar sistemas informatizados responden y se subsumen a los predicamentos de esta ideología esgrimida por 
Nuevas tecnologías, promesas y alienación tecnológica: una mirada crítica del fenómeno del voto electrónico como dispositivo técnico moderno

Morozov; "la necesidad de solucionar las cosas" $(2016,34)$ y una delegación constante al poder y facultades de la tecnología para dar respuesta a los múltiples problemas que aquejan a las sociedades occidentales y que se erigen como denominador común en la cultura técnica actual: "Las tecnologías se presentan hoy como la encarnación de los valores de una sociedad democrática: la libertad, la igualdad y el intercambio" (Busaniche y Heinz, 2008, 13). Y esos valores permean las promesas vertidas por quienes defienden enfáticamente su implementación.

A partir de la constatación de este triunfalismo, que en algunos casos roza una obsesión febril, resulta de vital importancia indagarse si se cumplen (o no) las promesas de optimizar los procesos de elección y de resolver los problemas de la política bajo los cánones de la modernización tecnológica, cuando lo que está en juego es la legitimidad de la democracia. Desde la perspectiva aquí tomada, la respuesta no es concluyente. Por un lado, entre otras ventajas, sus defensores pregonan:

a) su inestimable potencial de reducir el tiempo de espera para la obtención de resultados al agilizar los procesos de voto, conteo y tabulación de los datos registrados;

b) su capacidad de promover mayor accesibilidad y comodidad a los votantes;

c) el fomento de una mayor participación electoral gracias a la votación remota mediante Internet,

d) la disminución de gastos en términos de logística y de papel (Idea, 2012)

e) la emisión del voto mediado por nuevas tecnologías aparece como un motor para el fortalecimiento de las democracias al lograr, presuntamente, mayores niveles de transparencia al momento de ejercer el derecho ciudadano para votar.

Por otro lado, y más allá de algunas potencialidades propias de su constitución como sistema informático, cabe preguntarse si dichas potencialidades supone asumir los riesgos y costos que que trae consigo su introducción en términos de salud democrática. No es posible soslayar que los procesos que comprenden a los sistemas de e-voting vienen acompañados de variados problemas técnicos, legales y sociales que ponen en duda su presunta efectividad y capacidad transformadora: preservación del principio "one voter and one vote", amenazas en su sistemas de evaluación, seguridad y de confiabilidad puesto que el votante no puede garantizar si su emisión fue alterada o no (Alguliyev y Yusifov, 2018). En un tono

\footnotetext{
${ }^{6}$ Aunque cabe destacar que los gastos derivados del uso de tecnologías parecen contradecir ese ahorro seńalado. Empero, y como bien indica Chaparro $(2017,99)$, existen pocos estudios comparativos rigurosos entre los costos por voto emitido de boleta única en papel y su equivalente electrónico.
} 
Nuevas tecnologías, promesas y alienación tecnológica: una mirada crítica del fenómeno del voto electrónico como dispositivo técnico moderno

similar, Bishop y Wagner (2017) señalan que la introducción de tecnología para eliminar problemas propios de la votación en papel, es plausible de introducir otro tipo de inconvenientes que tensionan los sentimientos tecnofílicos que encierran sus intentos de aplicación. Sin papel, los votantes, no solo se encuentran imposibilitados de revisar si su voto fue registrado correctamente, sino también de validarlo de forma independiente (Bishop y Wagner, 2017).

Estos señalamientos buscan tomar distancia del pronunciado optimismo que suscita su adopción por parte de ciertos sectores de la esfera política, mediática y empresarial. Optimismo que hunde sus raíces en presupuestos de raigambre artefactual que orientan este carácter transformador y benefactor atribuido a la tecnología per se, y que reducen ampliamente la potencia propia de una evaluación de seguridad capaz de detectar y dejar en evidencia las vulnerabilidades de los equipamientos diseńados para votar electrónicamente. Desde una posición que asuma como objeto de análisis únicamente al software y al hardware, sin tomar en cuenta su real uso, limita su potencial valoración, siendo probable que dichos equipos de votación electrónica sean considerados, desde esta óptica artefactual, como óptimos y adecuados. Por consiguiente, es menester partir, expresa Lauer (2004), de un análisis de procedimiento que contemple los criterios de auditabilidad, integridad, confidencialidad y anonimato para alcanzar una real valoración de los pros y contras de dichos equipos que permita evaluar su pertinencia.

Como bien manifiestan muchos de sus detractores, los conocimientos necesarios (específicos) para auditar una elección, en una época signada por la gobernanza algorítmica, dejan de lado a un sector mayoritario de la ciudadanía, entre otras razones, al hallarse imposibilitados de saber lo que sucede en una urna electrónica; del nulo control del proceso electoral ante la falsa ilusión de transparencia que exhiben los mecanismos de voto por medio de una interfaz amigable y operable de forma intuitiva para quienes dispongan de conocimientos mínimos en materia informática. Dicha falta de control se agudiza cuando ciertos programas han sido escritos de forma deliberada para que no sean posibles de ser auditados (Busaniche, 2008). Este contexto de dependencia cognitiva e informacional da lugar a que sea una élite de especialistas, la encargada de velar, en última instancia, por nuestros derechos adquiridos a lo largo de la historia (se volverá más adelante con ello). La confianza plena depositada en la modernización del sistema electoral como solución encuentra problemas a la luz de distintos estudios que dan cuenta de su fragilidad y manipulabilidad propia de su constitución como sistema informático ${ }^{7}$, poniendo en riesgo la salud de los sistemas democráticos:

\footnotetext{
${ }^{7}$ A modo de ejemplo, Rezinicky expresa: "recientemente se han detectado fallas en sistemas de voto electrónico usados en EE. UU. por los cuales algunos votos "desaparecían” al trasladar los datos. Esas fallas estuvieron ahí durante más de 10 años y nadie las vio. Y lo que es peor aún, nunca vamos a saber cuántos ni cuáles votos se perdieron en elecciones reales usando esos equipos" $(2008,70)$.
} 


\footnotetext{
Marcelo José García Farjat

Nuevas tecnologías, promesas y alienación tecnológica: una mirada crítica del fenómeno del voto electrónico como dispositivo técnico moderno
}

El sistema de votación mediado por tecnologías inhabilita a los ciudadanos y ciudadanas del control del proceso electoral. Esto lo hace necesariamente menos democrático y, por lo tanto, menos legítimo. La realidad es que este sistema puede otorgar el control definitivo del acto electoral a quienes están en el poder. (Fundación Libre et al., 2017)

Las consideraciones anteriores tensionan las posibilidades de resolver los problemas que afronta la política tomando como único eje la inclusión de sistemas técnicos modernos. Como bien puntualiza Morozov (2016, 23), el solucionismo, y su voluntad de querer mejorar (casi) todo, se presenta inapropiado para abordar problemáticas como la aquí discutida:

El teórico del diseño Michael Dobbins acierta cuando dice que el solucionismo da por sentado el problema que intenta resolver, en lugar de investigarlo, y así llega a la respuesta antes de haber formulado las preguntas en toda su amplitud. Tiene tanta importancia la composición de un problema como el modo en que se resuelve. (Morozov, 2016, 24)

Otra línea de análisis similar sugiere pensar (retomando lo versado en el apartado anterior) en la confusión entre métodos y fines que permean a los intentos de modernizar los sistemas de votación que se trasluce en la adjudicación de capacidades mágicas a las nuevas tecnologías:

Un factor de adopción pocas veces considerado en la literatura es el del "prestigio tecnológico", una confusión de métodos y fines que supone que el uso de medios tecnológicos avanzados obra mágicamente para modernizar una democracia, o implica una aseveración sobre la modernidad de un gobierno o una autoridad electoral más que la solución a una necesidad específica. En la cadena de decisión y sustento del voto electrónico, puede ocurrir un fenómeno de introducción de error sistemático conocido como sesgo cognitivo, por la sobreapreciación de la tecnología: la fe en la tecnología puede enceguecer a los funcionarios públicos respecto de las cualidades negativas de las innovaciones, llevándolos a preferir una tecnología novedosa y compleja que puede ser inferior a una solución más antigua, más barata o más simple. (Chaparro, 2017, 100)

En virtud de lo dicho, su introducción (y en algunos casos, su posible reintroducción) demanda, por un lado, un análisis y exposición pormenorizados de sus ventajas y desventajas, abierto al consenso y debate ciudadano y político en aras de mantener la calidad e integridad de los sistemas democráticos y por otro, el examen y revisión críticos de los presupuestos que subyacen a los intentos de incorporar el uso de votación electrónica. Es imprescindible tomar en cuenta, no solo lo que presuntamente soluciona, sino también los problemas que se desprenden a raíz de su implementación, mas aun si se tiene en consideración al voto como derecho primario e inalienable, como un principio rector y fundamental de nuestras sociedades contemporáneas. 
En suma, lo que aquí se apunta es aquel desfase existente entre las necesidades y demandas que reclama una democracia política, y los intentos, arraigados en nociones solucionistas, de modernizar un sistema de votación con los riesgos y amenazas que conlleva y las dificultades propias de su conformación física, en un contexto que vanagloria el papel de las innovaciones en las sociedades atravesadas y subsumidas por el capital.

\section{Una mirada crítica acerca de las limitaciones de los enfoques deterministas tecnológicos para el abordaje de los sistemas de votación electrónicos}

El acentuado entusiasmo acerca de las capacidades transformadoras de las nuevas tecnologías no es casual ni fortuito. Hunde sus raíces en posturas deterministas, que, arraigadas en el sentido común, actúan como barreras epistémicas, axiológicas y cognitivas para la intelección de la complejidad inherente al desarrollo de los sistemas de votación electrónicos: la tecnología se halla en un plano externo que permea los cambios sociales, se presenta avalorativa, acrítica y universal, siguiendo un camino racional, ordenado y autónomo.

Bajo esta tesitura, se ignora su (real y complejo) funcionamiento, en tanto que los distintos mecanismos y lógicas que la conforman, son inaprensibles para los sujetos. Por consiguiente, el dispositivo del voto electrónico podría ser considerado, desde una óptica determinista, como un artefacto autónomo, sin carga axiológica, capaz de configurar y moldear, por sí sola, el porvenir de la política y de las sociedades. Si se lo concibiera desde su singularidad, sin contenido valorativo, alcanzaría con determinar los efectos, impactos y riesgos de su adopción en los cuerpos civilizatorios y proponer una tecnología más segura y confiable ante algunos problemas técnicos que encierran estos dispositivos. Pero este tipo de filiación conceptual y explicativa presenta un elevado grado de inadecuación e incompletitud, entre otros motivos, al soslayar la agencia artefactual, la íntima vinculación que se entreteje entre lo político y lo tecnológico y la propia complejidad inherente que envuelve a los procesos de conformación y concretización de cierto artefacto bajo determinadas circunstancias.

Profundizando lo expresado, las tesis deterministas, que encubren y avalan el establecimiento de gobiernos tecnocráticos, presuponen que la adopción de sistemas de votación electrónicos es un fenómeno inevitable e incluso deseable; enmarcadas en las bases del imperativo tecnológico (ya mencionado) que cimenta la gestación y producción de muchas de las tecnologías dominantes: “... si algo es técnicamente posible, entonces terminará por realizarse. Expresado de otro modo: en tecnología lo posible implica lo necesario; todo lo que esté alguna vez disponible, será necesariamente usado" (Diéguez Lucena, 2005, 73). Consecuentemente, uno de los principales puntos que subyace a los lineamientos de este imperativo descansa en la preeminencia que goza la realizabilidad y potencialidad técnicas; no existe limitación de ninguna índole al desarrollo técnico, 
Nuevas tecnologías, promesas y alienación tecnológica: una mirada crítica del fenómeno del voto electrónico como dispositivo técnico moderno

más allá de los límites propios de lo físico: "Inténtese todo, aplíquese todo, sin límite alguno" (Ramírez, 1998, 430). El carácter prescriptivo y normativo que lo envuelve se funda en la presunta irremediabilidad del desarrollo técnico, cuyo desenvolvimiento debe darse con independencia de todo tipo de apreciaciones y juzgamientos éticos y políticos, al interferir en la libertad de investigación y por obstaculizar su desarrollo y andamiaje.

En un razonamiento similar es posible ubicar a las tecnologías del voto electrónico en lo que Ferreras define como tecnología sitiadora:

Designo como "sitiadoras", a las tecnologías que recurren a saberes de expertos cada vez más opacos y aislados de la sociedad y que le otorgan un peso importante a la mercadotecnia. Condicionan así el acceso a ellas y su uso, favoreciendo a pequeños grupos de poder. Estas tecnologías se piensan para sociedades con niveles siempre crecientes de consumo, de productos cada vez más sofisticados que tienden a concentrar riquezas, decisiones y poder, bajo la promesa de un demorado derrame para todos. (Ferreras, 2019)

En función de lo señalado, y delante de una creciente sofisticación técnica que caracteriza a las sociedades digitales, el diseño y desarrollo de los sistemas de voto modernos se insertan en lógicas de producción y difusión de tecnologías hegemónicas y totalizantes bajo estilos tecnocráticos de gobernanza. Dicho esto, y bajo la tutela de ideas deterministas, la tecnología se presenta como una fuerza autónoma e independiente (e irrefrenable) sostenida por leyes específicas de carácter inexorable e inmutable, al margen de los intereses y deseos humanos. que rigen sus manifestaciones y comportamientos. En esta dirección, los artefactos, considerados solamente desde su naturaleza técnica, se hallan fuera de las posibilidades de control e intervención de los ciudadanos. Desde su propio diseño físico, se busca anular la capacidad participativa de los usuarios, siendo los especialistas los únicos capacitados en tomar decisiones para poder actuar e incidir sobre el desarrollo y devenir de los sistemas de votación electrónicos: "en cuanto a las decisiones que afectan nuestra vida, la democracia política ha estado largamente opacada por el enorme poder ejercido por los expertos de los sistemas técnicos“(Feenberg, s/f, párr. 1).

Superando nociones deterministas e instrumentalistas, caracterizadas por la infravaloración del carácter agencial de los artefactos, cabe destacar, siguiendo a Winner (2009), que las tecnologías encarnan formas de poder y de control, cuyo diseño ya posee una previsión de ciertas consecuencias (buscadas, pero no siempre logradas) al momento de su introducción por parte de políticos, empresarios e ingenieros. Mencionado esto, una revisión de orden conceptual que contemple y problematice sus orígenes y lo que sucede en la etapa de diseño es clave para entender, no solo su posterior conformación técnica y material, sino también sus posibilidades o limitaciones propias de su estructura física y sus implicancias ex post en las diferentes sociedades contemporáneas. Por consiguiente, un 
Nuevas tecnologías, promesas y alienación tecnológica: una mirada crítica del fenómeno del voto electrónico como dispositivo técnico moderno

requisito indispensable (empero no el único) para un abordaje más amplio acerca del comportamiento del sistema del voto electrónico reside en la consideración de la intencionalidad que carga su concepción y diseño, reflejada (en algún grado) en su producción final, al buscar que sea funcional y responda a los intereses de sus promotores ${ }^{8}$. Por otra parte, cabe subrayar que las distintas modalidades del desarrollo tecnológico, no solo comprenden factores técnicos, sino que se hallan íntimamente vinculadas con aspectos políticos, sociales, organizacionales, culturales y económicos: el funcionamiento o (no) de una tecnología no es una propiedad intrínseca del artefacto (Bijker, 2005), más bien es resultado de un interjuego entre factores técnicos y extra-técnicos (Thomas y Santos, 2016) que dan cuenta del funcionamiento y del devenir de un fenómeno técnico bajo circunstancias específicas. Dicho de otro modo, otra de las consecuencias palmarias de estas concepciones reduccionistas (que estructuran y guían al imaginario popular) radica en la omisión de su carácter particular, local y situado: la configuración y definición de un dispositivo técnico es fruto de complejos procesos de construcción social y cultural que responden a tramas de poder, alianzas, conflictos, negociaciones y disputas (Thomas, 2008); la tecnología es capaz de afectar y modificar profundamente la vida de las personas y nuestras sociedades (Pieters y Becker, 2005): la votación electrónica remota influye no solo para decidir si alguien decide participar en el proceso electoral, sino que, dependiendo del lugar de emisión, influye en la elección de los votantes, y en consecuencia, en los resultados (van den Besselaar y Oostveen, 2003). Desde esta línea de pensamiento, Hapsara et al. (2017) avanzan por sobre nociones reduccionistas que gobiernan y dan forma a las discusiones sobre la implementación de la votación electrónica, al destacar, no solo lo tecnológico, sino también el contexto organizacional en el cual se hace uso de dicha tecnología; elementos de vital importancia para situar el origen y causas de sus problemas y fallas. De forma similar, Thompson subraya la importancia que poseen los factores sociales y políticos de cada realidad nacional al momento de valorar y determinar su viabilidad: "no todo lo que funcionó bien en una realidad necesariamente se dará de la misma forma en otra" $(2013,111)$.

Estas nociones recién expuestas permiten alejarse de estas perspectivas que circunscriben la eficacia de los dispositivos de votación electrónica a criterios de verdad de carácter científico y universal. Criterios (de carácter hegemónico) que orientan y controlan el desarrollo humano y tecnológico, cuyos valores sociales y económicos aparecen vedados y fuera del radar de un amplio sector de la ciudadanía. Universalidad y cientificidad que sostienen la noción de neutralidad de los objetos técnicos que subyacen a los enfoques dominantes (instrumentalismo

\footnotetext{
${ }^{8}$ Si bien la cuestión referida a la plausibilidad (o no) de explicaciones intencionalistas excede ampliamente los objetivos del presente alcanza a destacar la complejidad inherente a las actividades de diseño: "El diseñador de artefactos desempeña un papel complejo ya que si bien no puede negarse que sus intenciones están en sus artefactos, la funcionalidad de los mismos a menudo va más allá de lo que el diseñador haya podido prever o planificar al momento de su concepción" (Magnani, 2006, 71).
} 
Nuevas tecnologías, promesas y alienación tecnológica: una mirada crítica del fenómeno del voto electrónico como dispositivo técnico moderno

y determinismo) que rigen la elaboración y planificación de muchas políticas de desarrollo y evaluación tecnológicas: la tecnología encargada de su transmisión a las oficinas centrales de registro, no tiene ningún tipo de influencia en el proceso de votación (Pieters y Becker, 2005) desde este cariz artefactual recién aludido. Desde un determinismo, la política tendría un papel subsidiario y residual, incapaz de ejercer injerencia directa sobre el devenir tecnológico, su papel se reduce a su potencial capacidad anticipatoria y a hacer usufructo de las bondades tecnológicas (Bijker, 2005); la tecnología resulta, entonces, indiferente a la política y escapa a cualquier intento de evaluación y control fruto de su presunta autonomía e independencia. Lo expresado da lugar a consideraciones tecnofóbicas y tecnopesimistas que inhiben el ejercicio de algún tipo de control sobre las dinámicas que asume el desarrollo tecnológico imperante, clausurando a la vez, las facultades de trazar un horizonte distinto que avizore un salto cualitativo en aras de una relación más democrática con la tecnología. Es común encontrar en estos enfoques la idea de que los objetos técnicos pueden ser usados tanto para el bien como para el mal, siendo los usuarios los únicos responsables de su empleo y de sus potenciales efectos y consecuencias perniciosos; mientras que la tecnología en sí misma, en este caso, el sistema y procesos de e-voting como tal, se halla exento de cualquier tipo de valoración o evaluación. Solo su empleo es plausible de ser juzgado:"será más bien el uso que se haga de ellos lo que plantee problemas éticos, políticos y sociales (González García, López Cerezo y Luján López, 2004, 1).

Puntualizando lo expresado, la noción de la neutralidad técnica se instrumenta a partir de un cuadro normativo universal de eficacia que separa la tecnología de sus contextos y condiciones sociales: votos son votos (Pieters y Becker, 2005), "un martillo es un martillo, una turbina a vapor, es una turbina a vapor" (Feenberg, 2012, 25) condensan y ejemplifican el espíritu instrumental recién aludido. Así, es posible encontrar en la arena político-mediática, discursos triunfalistas que destacan la necesidad de su implementación en vistas de las bondades que traen consigo distintos sistemas informáticos ya establecidos y naturalizados en la vida cotidiana: uso de cajeros automáticos, nuevas tecnologías para la educación y el comercio, por mencionar algunos; olvidando (o desconociendo) las diferencias significativas existentes entre los procesos de votación electrónica y el empleo de estos servicios online.

\section{Los sistemas electrónicos de votación como tecnologías alienantes}

Bajo el amparo de las sociedades informacionales, y como bien se viene expresando a lo largo del trabajo, se observa como un sector mayoritario de la ciudadanía ignora la capacidad de modelamiento y significación de la actividad humana por obra de los desarrollos tecnológicos. Llegados a este punto, resulta necesario realizar un comentario adicional (que retoma lo explicitado en párrafos precedentes) de particular interés para anclar lo que se pretende discutir en este apartado: el dispositivo del voto electrónico se ubica en lo que Winner (2009) 
Nuevas tecnologías, promesas y alienación tecnológica: una mirada crítica del fenómeno del voto electrónico como dispositivo técnico moderno

entiende como sonambulismo tecnológico: aparece operando como un mero instrumento o medio de uso limitado, pasivo y ocasional, cuyos propósitos e intenciones se presentan claros y aproblemáticos para el ciudadano: facilitar y agilizar los procesos de votación y escrutinio gracias a las capacidades transformadoras de las nuevas tecnologías.

Tomando en consideración lo señalado, se precisa proponer un concepto más amplio y abarcador de tecnología que supere su inmediata identificación con lo maquínico, a lo estrictamente artefactual, esto es, como herramienta y dispositivo listos para ser empleado, donde medios y fines aparecen disociados. A raíz de este reduccionismo, su dimensión cognitiva (las tecnologías como resultado de una multiplicidad de conocimientos diversos, incluido el científico) y su dimensión sistémica (las innovaciones tecnológicas se diseñan, se desarrollan y se difunden en contextos que comprenden a una amplia gama de elementos heterogéneos técnicos y extra-técnicos que la conforman) se encuentran fuera de escena en la relación del sujeto con la tecnología: "el individuo aislado tiene la impresión de vivir al margen de los procesos que llevan a la producción de las nuevas tecnologías" (Diéguez Lucena, 2005, 80), conducente a un quietismo acrítico generalizado que se configura a partir de su presunta imposibilidad de cuestionar o de intervenir en las direcciones que asumen los dispositivos de votación electrónicos, debiéndose conformar con los medios disponibles que pueblan el universo social para ejercer el derecho al sufragio.

En un pensamiento similar, Winner (2009) entiende que una explicación funcional e instrumental se muestra incapaz de aprehender el carácter performador de las tecnologías, en tanto portador de cambios identitarios que configuran y moldean nuestro universo cotidiano. El sonambulismo tecnológico descrito por Winner se intensifica, entre otras razones, a medida que se complejiza el saber técnico, en donde parte de la ciudadanía se halla imposibilitada de dar cuenta de los procesos que conforman a la tecnología y de muchos de sus efectos: "usamos la tecnología, pero no la comprendemos, ni la controlamos ...la gran mayoría de la ciudadanía tiene dificultades para explicar de qué se trata Internet, cómo funciona... distinguir un sistema operativo de una aplicación" (Fundación Libre et al., 2017). Y en este marco de desconocimiento y extrańamiento tecnológicos, los sistemas de votación electrónicos no escapa a dicha propensión:

Es difícil comprender cómo un proceso opaco se haría más transparente mediante el recurso de agregarle una "caja negra”. Lejos de aportar a la transparencia, la urna electrónica obstaculiza la capacidad de la mayoría de los ciudadanos de fiscalizar la elección. (Fundación Libre et al., 2017)

En un pensamiento similar, Neumman (2018) expresa:

Si la computadora está programada para que el voto individual sea verificable, como tiene que ser, se viola el voto secreto. Y si se quiere respetar el voto secreto, las elecciones ya no podrán ser verificables. Así que el Chaos 
Nuevas tecnologías, promesas y alienación tecnológica: una mirada crítica del fenómeno del voto electrónico como dispositivo técnico moderno

Computer Club respalda totalmente el fallo de la Corte Constitucional Alemana en que no es viable introducir el voto virtual sin violar el derecho fundamental al voto secreto y verificable. El voto con papel y lápiz es el único que podemos defender, en nombre de la democracia y la seguridad.

En este escenario de denuncias, lo sucedido en las elecciones de 2013 en Estonia representa un significativo ejemplo de los problemas de seguridad que alberga la votación electrónica:

Transparency measures, such as video recordings and published source code, were incomplete and insufficient to allow outside observers to establish the integrity of results ... Cyberwarfare, once a largely hypothetical threat, has become a well documented reality, and attacks by foreign states are now a credible threat to a national online voting system. (Springall $e t$ al., 2014, 703)

Estas dificultades no son casuales o fortuitas. Por el contrario, son fruto de la propia conformación de estos aparatos, cuyo diseño e implementación ignoran principios básicos y fundamentales de seguridad que ponen en riesgo la integridad de los resultados:

For example, malicious code could exploit vulnerabilities in the voting software to spread virally from machine to machine. As a result, when the voting machines return results to election central to count the votes, a virus could infect the county's election management systems. At the next election, the infected election management systems could then infect every voting machine in the county. (Bishop y Wagner, 2007, 120)

Desde estas apreciaciones introductorias acerca de la conformación física de estos dispositivos, y tomando en cuenta las potenciales amenazas recién descritas, el sistema de voto electrónico es concebido como un entrelazamiento de "cajas negras", cuya comprensión de sus mecanismos de funcionamiento técnico se tornan inaccesibles, no solo por los conocimientos especializados que demanda su uso, sino también por la incapacidad de intervenir y ejercer control, por parte de la ciudadanía, sobre dicho artefacto y su conformación y devenir. Y en consecuencia, de lo que sucede efectivamente dentro de una urna electrónica, a raíz de su propia impenetrabilidad estructural:

Para poder garantizar qué es exactamente lo que está haciendo una urna electrónica hay que ser especialista en sistemas de información, programación, compiladores, sistemas operativos y microelectrónica, además de tener las herramientas que permitan examinar los dispositivos a fondo. Hay pocos equipos de especialistas capaces de reunir estos conocimientos y ciertamente ningún individuo por sí mismo puede asegurar qué está pasando en una urna electrónica. (Rezinovsky, 2008, 69-70) 
Nuevas tecnologías, promesas y alienación tecnológica: una mirada crítica del fenómeno del voto electrónico como dispositivo técnico moderno

Esta imposibilidad, propia de la constitución material de estos sistemas, permite graficar la asimetría existente entre expertos y no-expertos en materia científico-tecnológica, intensificada tras la irrupción finisecular de las nuevas tecnologías. Esta asimetría entre el saber productivo y el uso tecnológico no es algo nuevo: con el advenimiento de las técnicas eléctricas en el siglo XIX, la brecha entre la ascendente complejidad del saber tecnológico y la simplificación del uso para los usuarios, es cada vez mayor (Quilomba, 2017). Pero dicha brecha se "subsana" y se acorta, de acuerdo a Cabrera (2006), mediante la creencia tecnológica: la consigna es hacer "transparente" la tecnología, facilitar su acceso y uso a las personas; la transparencia con la que opera la tecnología esconde la complejidad de su condición computacional (Cabrera, 2021, 141). En esta trama, el aparato tecnológico aparece como "una maravilla técnica" que se halla al alcance de cualquier sujeto, y en este sentido, el dispositivo del voto electrónico parece no poder escapar a la actual relación de dependencia y sumisión de los sujetos a los objetos técnicos y digitales que orbitan en nuestra cotidianidad: interactuamos con artefactos sin sentirlos (Broncano, 2006).

Estas valoraciones de carácter crítico, encargadas de diagnosticar y graficar la actual relación de los sujetos con la técnica, se sitúan bajo el amparo del concepto de alienación tecnológica que caracteriza al modelo de desarrollo tecnológico capitalista propuesto por Quintanilla, Parselis, Sandrone y Lawler (2017). Estos autores, no solo esbozan una mirada crítica acerca de la presente relación con la tecnología, sino que también establecen un modelo alternativo de desarrollo tecnológico concebido como tecnologías entrañables ${ }^{9}$, aplicable para pensar en una relación más democrática con las tecnologías. Siguiendo este razonamiento, sus contribuciones resultan de particular interés para ubicar a los dispositivos de voto electrónico como fiel representante de la alienación tecnológica. La opacidad estructural que caracteriza al diseño de los objetos, es una de las fuentes de alienación tecnológica (Quintanilla, 2017); erigiéndose, de este modo, como una tecnología incompatible con los requerimientos de una sociedad democrática:

La certeza sobre la intención del votante se vuelve más difusa por la existencia de un mecanismo de expresión controlado por un programa informático que el votante desconoce (y es a veces desconocido también para las autoridades electorales), y que es imposible analizar sin un conjunto de conocimientos altamente especializados (Chaparro, 2017, 93).

\footnotetext{
${ }^{9}$ Quintanilla (2017) las define como aquellas tecnologías no alienantes que son diseñadas para evitar la opacidad estructural y para el ejercicio de un control moralmente responsable sobre su desarrollo. Como bien indican Sandrone y Lawler (2017), el desarrollo tecnológico supone responsabilidades morales y políticas, en donde la construcción de cajas negras deben quedar reducidas a su mínima expresión. Así, en contraposición a tecnologías cerradas y ajenas, se promueven, entre otras características, tecnologías abiertas basadas en el consenso y deliberación ciudadanas.
} 
Nuevas tecnologías, promesas y alienación tecnológica: una mirada crítica del fenómeno del voto electrónico como dispositivo técnico moderno

Como bien señala Flusser (2017), los aparatos funcionan y nos hacen funcionar bajo esa idea de "caja negra" que nos ubica como simples funcionarios que ignoran lo que acontece al interior de ellos. Este pensamiento flusseriano se replica con intensidad en tiempos de expansión de las nuevas tecnologías, en un universo signado por el creciente consumo de tecnologías cada vez más complejas y eficientes (en términos técnicos), pero a la vez, más lejanas y opacas (Lawler y Sandrone, 2017). Y en este sentido, los dispositivos de votación electrónica dan cuenta de esta ascendente complejidad técnica que inunda nuestra cotidianidad mediada por lo neotecnológico. Estos dispositivos forman parte de una cultura técnica caracterizada por el no-reconocimiento de la significación y esencia de los objetos industriales que pueblan el universo social y tecnológico, "por su omisión en la tabla de valores y de conceptos que forman parte de la cultura" (Simondon, 2017, 32) que se traduce en un tecnicismo idólatra que encuentra en la máquina, la potencia de su deseo: "los trata como puros ensamblajes de materia, desprovistos de verdadera significación, y que presentan solamente una utilidad" (Simondon, 2017, 32).

Aquí resulta oportuno recuperar aquellas nociones que advierten sobre aquel sentimiento de lejanía que priman en nuestra relación con los fenómenos tecnológicos, de los artefactos que usamos a diario, pero que no conocemos ni podemos explorar en una trama que excluye a los ciudadanos y su capacidad de agenciamiento epistémico y cognitivo en las etapas de concepción, diseńo y evaluación tecnológicas. En efecto, el actual modelo de tecnologías hegemónicas, opacas y cerradas que subyace a las narrativas capitalistas, consagra y preforma, unilateralmente, distintos tipos de consumidores: "la producción está determinada por los productores, y no por las decisiones de los consumidores" (Parselis, 2015, 73). De acuerdo al recién citado Parselis (2017), se asiste a una desvinculación técnica y social, que se constata en las reflexiones vertidas a lo largo del trabajo sobre la materia temática concerniente. Tomando como eje una noción relacional e interactiva de la vida de un artefacto, existe un desacoplamiento entre los contextos de diseño y de uso, entre los objetivos explícitos e implícitos que estructuran al desarrollo e implementación de los sistemas electrónicos de votación que encuentra en los usuarios, un papel reactivo y subsidiario, circunscripto al mero acto de votar. Lo dicho implica aceptar que, en los planes de diseño y ejecución de estos sistemas, existen decisiones que viabilizan y fomentan esta desvinculación y relación de extrańamiento con lo tecnológico. Su omnipresencia y su naturalización como simple instrumento de uso que nos facilita y agiliza el proceso de votación, actúan como vectores que cimentan y fortalecen ese extrańamiento; la alienación de orden tecnológico imperante expuesta por Quintanilla (2017) viene a sintetizar la relación actual que se entreteje entre un vasto sector de la ciudadanía y los sistemas electrónicos de votación como fruto de la cultura técnica imperante. 


\section{Consideraciones finales}

La introducción (o no) del voto electrónico es una problemática candente (aunque ahora relegada en tiempos de pandemia) en donde el debate y la exposición de sus dificultades juegan un rol significativos al permitir visibilizar y alertar a los ciudadanos acerca de las consecuencias y efectos negativos que conlleva su aplicación. Pero más allá de los consabidos riesgos de su implementación, las cavilaciones vertidas a lo largo del trabajo buscaron dejar al descubierto ese cariz determinista y solucionista que impregna a los discursos públicos que avalan y promueven, con carácter de urgencia sistémica, la necesidad de modernizar los sistemas electorales. Intentos de modernización que ponen en riesgo varios de los derechos inalienables que hemos adquirido a lo largo de la historia y que amenazan seriamente la salud de las democracias: "la modernidad tecnológica no siempre es mala, pero eso no implica que sea próspera en todos los sentidos, y que siempre sea lo mejor (Fundación Libre et al., 2017)”.

Lejos de posturas reduccionistas que animan a los estudios sobre los efectos e impactos de la tecnología, algo que nos permite el abordaje sobre el dispositivo del voto electrónico, es apuntar a los fenómenos tecnológicos desde su complejidad y peculiaridad, en el marco de una cultura técnica signada por una relación de desconocimiento y extrañamiento con los objetos técnicos y digitales, de su naturaleza y significancia que, en última instancia, nos hace olvidar su carácter humano y mediador con la naturaleza y su capacidad de organizar nuestras experiencias. Paralelamente, se habilita la posibilidad de poner en tensión aquel sentido común que hunde sus raíces en nociones artefactuales e instrumentales, cuya concepción de dichos objetos se limita a criterios físicos y de funcionamiento y diseños adecuados y eficaces que omiten los distintos procesos de orden social, político y cultural que envuelven a las tecnologías. Si es considerada como una fuerza exógena y separada de la sociedad, cuya expresión y desarrollo se rigen bajos leyes propias e inmutables, al margen de cualquier posible intervención humana, pareciera difícil pensar en sociedades tecnológicas más democráticas en un ambiente que asume la centralidad de tecnologías hegemónicas que discurren y se propagan bajo la tutela de expertos y del poder político y económico.

Este tipo de tecnologías sitiadoras y alienantes que avalan estilos tecnocráticos de gobernanza, favorecen decididamente la participación e intervención de expertos, quienes, a partir de criterios objetivos y científicos, deciden qué tecnologías implementar (y cómo y cuándo), y consecuentemente, se arrogan la capacidad de tomar decisiones, de particular relevancia en el devenir de nuestros sistemas democráticos. Pensando en los dispositivos de votación electrónica, lo dicho se agudiza al advertir que su diseño y funcionamiento se bajo la forma de una caja negra para los votantes, inhabilitados, por su propia estructura y configuración físicas, de conocer e interpretar sus mecanismos, objetivos y prestaciones; de lo que sucede dentro de una urna electrónica. En definitiva, este cajanegrismo los excluye de cualquier tipo de intervención sobre el comportamiento y funcionamiento 
Nuevas tecnologías, promesas y alienación tecnológica: una mirada crítica del fenómeno del voto electrónico como dispositivo técnico moderno

de dicho dispositivo. En otras palabras, en tiempos de convivencia ubicua con tecnologías alienantes, los sistemas de votación electrónicos aparecen como un fiel emblema de esta relación de sumisión y de encadenamiento a los objetos que pueblan y orbitan en nuestra cotidianidad, donde el ciudadano dispone de un papel pasivo y marginal en toda esta trama neotecnológica; se constituye como un ente despersonalizado que consume (Giraldo, 2012), incapaz, en términos kantianos, de abandonar su minoría de edad.

Las sociedades tecnológicas, como bien indica Feenberg (2012), parecen estar condenadas a una dirección autoritaria, lo que sería un obstáculo significativo para pensar en opciones viables capaces de lograr sociedades diferentes. Pero como bien indica el filósofo canadiente, que la tecnología moderna sea más compatible con gobiernos autoritarios, no implica descartar la idea de que, bajo otros contextos sociales, pueda ser empleada de un modo más democrático. Los valores antidemocráticos que permean y rigen al desarrollo tecnológico nos obliga a pensar en modelos y concepciones alternativas que reconozcan la necesidad de una mayor y efectiva participación e intervención de los ciudadanos en la res pública: "el diseño de las tecnologías es, consecuentemente, una decisión ontológica plena de consecuencias políticas $(2012,22)$.

Ante la presunta inevitabilidad del progreso tecnológico y el deber heterodirigido de adaptación y de conformidad de los sujetos a las nuevas tecnologías, señaladas y promovidas por el imperativo tecnológico, cabe preguntarse con Parselis (2018): ¿deberíamos asumir que el desarrollo tecnológico no puede darse de otro modo? El determinismo nos invita a la pasividad, a un quietismo acrítico que nos obliga a aceptar los desarrollos tecnológicos tal como se presentan y amoldarnos a ellos, sin exigencia de cualquier tipo de responsabilidad moral y social en una época signada por la presión ubicua de las tecnologías que nos rodea. Situación que se presenta como barrera para imaginar y delimitar un horizonte de cambio que posibilite la concepción y trazamiento de modelos alternativos y democráticos más compatibles con los valores de la libertad, la justicia y la participación sociales. Esta pasividad no es arbitraria, puesto que es posible situarla como fruto de la denominada profecía de autocumplimiento, es decir, de aquellas creencias que discurren y estructuran nuestro comportamiento cotidiano y que guían nuestros modos de pensamiento y de interacción: "si todos consideramos que la tecnología no es controlable, nadie hará los esfuerzos necesarios para fomentar su control" (Diéguez Lucena, 2005, 83).

En síntesis, no se trata de demonizar ni de rechazar acríticamente la inclusión de las nuevas tecnologías en los sistemas de votación. Más bien se debe pensar en su optimización a partir de modelos alternativos (y más amplios) que habiliten la participación de los ciudadanos en los modelos de evaluación tecnológica, que formen parte de las decisiones tecnológicas y que se valorice sus experiencias y saberes en tanto agentes epistémicos. Las fortalezas y debilidades demostradas de los sistemas ya implementados pueden informar a los otros países acerca de una 
Nuevas tecnologías, promesas y alienación tecnológica: una mirada crítica del fenómeno del voto electrónico como dispositivo técnico moderno

adopción más segura de un sistema informatizado así como su diseño en términos de investigación y práctica (Springall et al., 2004). Frente a las múltiples fallas y riesgos que trae consigo su introducción, se torna primordial encontrar otros mecanismos que permitan que los ciudadanos sean capaces de ejercer libremente su derecho a votar, es decir, sin socavamiento de ninguno de los derechos que fueron ganados a lo largo de la historia: el voto libre, secreto y universal.

Si la tecnología representa los planos, propósitos y valores de nuestra sociedad (González García et al., 2004, 4), una opción de particular significancia reside en la producción y difusión de tecnologías abiertas, polivalentes y comprensibles, tal como promueve el modelo de tecnologías entrañables, compatibles con los valores de la justicia, la libertad y del respeto. Esto es, tecnologías diseñadas para ser controladas por la ciudadanía, cuyas necesidades y demandas sean contempladas al momento de su concepción y desarrollo. En este sentido, y siguiendo a Feenberg (2012), urge su democratización: "Hacer tecnología es, sin duda, hacer política y, puesto que la política es un asunto de interés general, deberíamos tener la oportunidad de decidir qué tipo de tecnología deseamos" (González García et al., 2004, 4).

Aunque la presente propuesta de análisis permitirá expandir puntos de vista acerca de la complejidad inherente a la conformación y funcionamiento del dispositivo del voto electrónico bajo la actual cultura técnica, se requerirá de investigaciones futuras que habiliten, no solo ampliar las críticas hacia este dispositivo desde distintas posiciones y miradas, sino también abrir puertas a propuestas y marcos teóricos superadores. Es decir, escudriñar y discutir modelos alternativos de desarrollo tecnológico que avizoren una relación más democrática, libre y justa en un ambiente que entroniza el potencial transformador de las nuevas tecnologías y la eficiencia técnica de los artefactos. En efecto, los objetivos del trabajo limitaron el desarrollo de estas contribuciones, pero resultan de vital importancia para un entendimiento más profundo y cabal de las problemáticas que encierran los dispositivos del voto electrónico. También, a partir de su valoración como fiel representante de una tecnología alienante y hegemónica, considerar y aplicar modelos tecnológicos más inclusivos y democráticos en el que los ciudadanos, reducidos al papel de consumidores, sean capaces de ejercer su derecho de participar, consensuar e intervenir en las trayectorias que asume el desarrollo y cambio tecnológicos, sobre el diseño e innovaciones tecnológicas, de particular relevancia en el devenir de los cuerpos civilizatorios.

\section{Referencias bibliográficas}

Abu-Shanab, Emad, Knight, Michael, Refai, Heba (2010). E-Voting systems: A tool for e-democracy. Management Research and Practice, 2(3), 264-274. https://www. researchgate.net/publication/227490182_E-voting_systems_A_tool_for_edemocracy

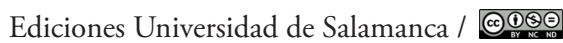

ArtefaCToS, Vol. 10, No. 2 (2021), 2. ${ }^{\text {a }}$ Época, 71-99 
Nuevas tecnologías, promesas y alienación tecnológica: una mirada crítica del fenómeno del voto electrónico como dispositivo técnico moderno

Aguerre, Tomás (2017). Voto electrónico. Un debate entre lo seguro y lo moderno. En Busaniche et al. (comps.), Voto electrónico: una solución en busca de problemas (pp. 37-53). Buenos Aires: Tren en Movimiento. https://www.vialibre.org.ar/wpcontent/uploads/2007/11/ve-solucion-busca-problemas.pdf

Alguliyev R., Yusifov, F. (2018). Multi-Criteria Evaluation of Electronic Voting System Security Threats. Вопросы кибербезопасности, 3(27), 16-21. https://doi. org/10.21681/2311-3456-2018-3-16-21

Beck, Ulrich (1998). La sociedad del riesgo. Hacia una nueva modernidad. Buenos Aires: Paidós.

Bijker, Wiebe (2005). Why and How Technology Matters? En Goodin, R. y Tilly, C. (eds.), Oxford Handbook of Contextual Political Analysis. Oxford: Oxford University Press.

Bishop, Matt, Wagner, David (2007). Risk of E.voting. Computer Science. Communication of ACM, 50(11), 120. https://doi.org/10.1145/1297797.1297827

Broncano, Fernando (2006). Entre ingenieros y ciudadanos. Madrid: Limpergraf.

Busaniche, Beatriz (2008). Lo que cuenta no son los votos, sino quien cuenta los votos. En Busaniche, Beatriz, Heinz, Federico, Rezinovsky, Alfredo et al. (comps.), Voto electrónico. Los riesgos de la ilusión (pp. 73-76). Córdoba: Fundación Vía Libre. https://www.vialibre.org.ar/wp-content/uploads/2009/03/evoto.pdf

Cabrera, Daniel Horacio (2006). Lo tecnológico y lo imaginario. Las nuevas tecnologías como creencias y esperanzas colectivas. Buenos Aires: Biblos.

Cabrera Altieri, Daniel Horacio. (2021). El algoritmo como imaginario social. ZER: Revista De Estudios De Comunicación = Komunikazio Ikasketen Aldizkaria, 26(50), 125-145. https://doi.org/10.1387/zer.22206

Cabrera Altieri, Daniel Horacio, Egea, María Angulo (2020). Lo imaginario de las narrativas algorítmicas. Perspectivas de la Comunicación, 13(1), 13-28, Temuco: Universidad de La Frontera. https://doi.org/10.4067/S071848672020000100013

Castells, Manuel (1996). La era de la información: economía, sociedad y cultura. Vol. 1. México: Siglo XXI.

Chaparro, Enrique (2017). Objeciones a los sistemas de voto electrónico. En Busaniche et al. (comps.), Voto electrónico: una solución en busca de problemas (pp. 89-116). Buenos Aires: Tren en Movimiento. https://www.vialibre.org.ar/wpcontent/uploads/2007/11/ve-solucion-busca-problemas.pdf

De Barros, Manuela (2018). Arqueología de medios. La tecnología desde una temporalidad difusa. Herder: México.

Deustche Welle (2018). Chaos Computer Club en Alemania: elecciones con voto electrónico no respetan principios democráticos, Deustche Welle 28 de diciembre. https://www.dw.com/es/chaos-computer-club-en-alemania-elecciones-con-votoelectr\%C3\%B3nico-no-respetan-principios-democr\%C3\%A1 ticos/a-46890571 
Nuevas tecnologías, promesas y alienación tecnológica: una mirada crítica del fenómeno del voto electrónico como dispositivo técnico moderno

Diéguez Lucena, Antonio (2005). Determinismo tecnológico: indicaciones para su interpretación. Argumentos de Razón Técnica, 8, 67-87. https://core.ac.uk/ download/pdf/51385452.pdf

Idea Internacional (2012). Una introducción al voto electrónico. Consideraciones esenciales. Estocolmo: IDEA Internacional. Serie de recursos sobre procesos electorales. http://www.defensoria.org.ar/wp-content/uploads/2015/06/IntroducingElectronic-Voting-Essential-Considerations-Spanish-PDF.pdf

Feenberg, Andrew (2012). Transformar la realidad. Una nueva visita a la teoría crítica. Buenos Aires: Universidad Nacional de Quilmes.

Feenberg, Andrew (s/f). Racionalización democrática: tecnología, poder y libertad. https://www.sfu.ca/ andrewf/demspanish.htm

Ferreras, Manuel (2019). Tecnologías, elecciones y comunicación. https://alreves.net.ar/ tecnologias-elecciones-y-comunicacion/?fbclid=IwAR38zFBIWTh13nv0N2mncyc7-BaZ7xZOxbBPN-aaHxQA1fbh_Ld3i2jrKo.

Fundación Vía Libre, Un Viaje Cine y Quilomba. (2017). El mito del voto electrónico. Caja Negra: Argentina [Archivo de video]. https://www.youtube.com/ watch?v=zhjVVrVHsrQ.

Flusser, Vílem (1990). Hacia una filosofía de la fotografía. México: Trillas.

Flusser, Vílem (2017). El universo de las imágenes técnicas. Elogio de la superficialidad. Buenos Aires: Caja Negra.

González García, Marta, López Cerezo, José, Luján López, José (2004). El estudio social de la ciencia y la tecnología. Ciencia, Tecnología y Sustentabilidad, El Escorial, julio, 1-16. http://istas.net/descargas/escorial04/material/dc06.pdf

Giraldo Gutiérrez, Francisco Luis (2012). Técnica y tecnología: el dilema del sujeto racional en la sociedad de consumo. Estudios de Filosofía, 46, 25-39. Universidad de Antioquia Medellín, Colombia. https://www.redalyc.org/ pdf/3798/379837132003.pdf

Guevara Pezoa, Felipe (2019). Eurekadabra: ciencia, tecnología y magia. PAAKAT: revista de tecnología y sociedad, 9(16), https://doi.org/10.32870/pk.a9n16.389

Lash, Scott (2006). Crítica de la información. Madrid: Amorrortu.

Lauer, Thomas (2004). The Risk of e-Voting. Electronic Journal of e-Government, 2, 177-186. http://profs.sci.univr.it/ - giaco/download/Watermarking-Obfuscation/ voting.pdf

Loeber, Leontine (2014). E-voting in the Netherlands; past, current, future? Proceedings of the 6th international conference on electronic voting (EVOTE). TUT Press, Tallinn, pp.43-46. Disponible en: https://www.researchgate.net/ publication/301547849_E-voting_in_the_Netherlands_past_current_future 
Nuevas tecnologías, promesas y alienación tecnológica: una mirada crítica del fenómeno del voto electrónico como dispositivo técnico moderno

Hamra, Manik, Imran, Ahmed, Turner, Timothy (2017). E-Voting in Developing Countries Current Landscape and Future Research Agenda. R. Krimmer et al. (eds.), E-Vote-ID 2016, LNCS 10141 (pp. 36-55). Cham: Springer International Publishing AG.

Magnani, Lorenzo (2006). La moralidad distribuida y la tecnología. Cómo las cosas nos hacen morales. Isegoría, 34, 63-78. http://isegoria.revistas.csic.es/index.php/ isegoria/article/view/4

Montes, Miguel, Penazzi, Daniel, y Wolovick, Nicolás (2016). Consideraciones sobre el voto electrónico. SIE 2016, 10 Simposio de Informática en el Estado. http:// sedici.unlp.edu.ar/bitstream/handle/10915/58355/Documento_completo.PDFPDFA.pdf?sequence $=1$ \&isAllowed $=y$

Morozov, Evgeny (2016). La locura del solucionismo tecnológico. Buenos Aires: Katz.

Musso, Pierre. (2009). Usages et imaginaires des tIC. L'évolution des cultures numériques, FYP éditions, 201-210. https://hal-imt.archives-ouvertes.fr/file/index/ docid/479606/filename/Usages_et_imaginaires_des_TIC.pdf

Nardi, Joel y Maenza, Rosa (2017). Voto Electrónico, Vulnerabilidades y Soluciones para evitar ataques.SID, Simposio Argentino de Informática y Derecho. http:// sedici.unlp.edu.ar/handle/10915/65209

Neumann, Linus (2019). Die Urne ist eine geniale Erfindung, 25 de octubre, Suddeutsche Zeintung. https://www.sueddeutsche.de/digital/spd-vorsitzabstimmung-1.4655703

Panizo Alonso, Luis (2007). Aspectos tecnológicos del voto electrónico. http://www. onpe.gob.pe/modEducacion/Publicaciones/I-2-2-017.pdf.

Parselis, Martín (2017). Repensando la relación entre diseñadores y usuarios a través de las tecnologías entrañables. En Quintanilla, Miguel, Parselis, Martín, Sandrone, Darío. y Lawler, Diego (eds.), Tecnologías entrañables. Madrid: Catarata. 54-80.

Parselis, Martín (2018). Dar sentido a las técnicas. ¿Pueden ser honestas las tecnologías? Madrid: Catarata.

Pieters, Wolter \& Becker, Marcel (2005). Ethics of e-voting. An essay on requirements and values in Internet elections. En P. A. E. Brey, F. S. Grodzinsky, L. D. Introna (Eds.), Ethics of new Information technology: Proceedings of the Sixth International Conference of Computer Ethics (CEPE 2005) (pp. 307-318). Centre for Telematics and Information Technology (CTIT). https://research.utwente.nl/en/ publications/ethics-of-e-voting-an-essay-on-requirements-and-values-in-internet

Quintanilla, Miguel Ángel (2017a). Tecnologías entrañables. Un modelo alternativo de desarrollo tecnológico. En Quintanilla, Miguel, Parselis, Martín, Sandrone, Darío y Lawler, Diego (eds.), Tecnologias entrañables (15-53). Catarata: Madrid.

Quintanilla, Miguel Ángel (2017b). Tecnología. Un enfoque filosófico y otros ensayos sobre filosofía de la tecnología. México: Fondo de Cultura Económica. 
Nuevas tecnologías, promesas y alienación tecnológica: una mirada crítica del fenómeno del voto electrónico como dispositivo técnico moderno

Ramírez, Edgar (1998). Crítica al imperativo tecnológico. Revista Filosofía, Universidad de Costa Rica, XXXVI(88/89), 429-432.

Rezinovsky, Alfredo (2008). La certeza de la incertidumbre: lo que no se dice sobre el Voto Electrónico. En Busaniche, Beatriz, Heinz, Federico, Rezinovsky, Alfredo et al. (eds.), Voto electrónico. Los riesgos de la ilusión (pp. 69-71). Fundación Vía Libre: Córdoba. https://www.vialibre.org.ar/wp-content/uploads/2009/03/ evoto.pdf

Sartori, Giovanni (1998). Homo Videns. La sociedad teledirigida. Buenos Aires: Taurus.

Springall, Drew, Finkenauer, Travis et al. (2014). Security Analysis of the Estonian Internet Voting System. CCS'14, November 3-7, 2014, Scottsdale, Arizona, USA. ACM 978-1-4503-2957-6/14/11. http://dx.doi.org/10.1145/2660267.2660315

Striphas, Ted (2015). Algorithmic culture. European Journal of Cultural Studies, 2015, 18(4-5), 395-412. https://doi.org/10.1177/1367549415577392

Thomas, Hernán (2008). Estructuras cerradas vs. Procesos dinámicos: Trayectorias y estilos de innovación y cambio tecnológico. En Thomas, H. y Buch, A. (Coord.), Actos, actores y artefactos. Sociología de la tecnología. (pp. 63-101). Bernal: Universidad Nacional de Quilmes.

Thomas, Hernán y Santos, Guillermo (2016). Tecnologias para incluir. Ocho análisis socio-técnicos orientados al diseño estratégico de artefactos y normativas. Argentina: Lenguaje Claro.

Thompson, José (2013). Algunas notas acerca del uso de la tecnología y del voto electrónico en la experiencia electoral de América Latina. Revista IIDH, 58, 102 129. https://www.corteidh.or.cr/tablas/r32365.pdf

Van den Besselaar, Peter, Oostveen, Anne-Marie (2003). E-voting technology is notneutral! EnKlausDittrich etal.(eds.),Informatik2003, InnovativeInformatikanwendungen, Band 2. Lecture Notes in Informatics P-35 (pp. 218-221). http://citeseerx.ist.psu. edu/viewdoc/download?doi=10.1.1.96.3368\&rep=rep1\&type=pdf

Winner, Langdon (2016). Decadencia y caída del tecnotriunfalismo. REDES, Vol.22, Núm.23, Diciembre de 2016, 127-142. http://www.unq.edu.ar/advf/ documentos/58e4ec4bbb809.pdf 